\title{
Determining Optimal Size and Placement of Renewable DG Considering Variation of Load
}

\author{
Kumari Sandhya Rani, Surajit Sannigrahi, Parimal Acharjee, Aashish Kumar Bohre
}

\begin{abstract}
An advance algorithm to decide optimal size and place of renewable DG by applying adaptive particle swarm optimization (A-PSO) technique is reported in this work. A multiobjective function has been proposed to improve voltage profile, maximize economic benefit and reduction in active power losses. This work includes renewable energy sources based distributed generation (DG) technique like solar and biomass DGs. The time variations characteristics for solar DG and load have been considered in the system. Due to the problem of easily get trapped into local optima, particle Swarm optimization (PSO) may not be able to solve complex power system problems. Hence, APSO with variable weight function has been used in this work. The implementation of proposed technique has been presented for practical 94-bus portuguese radial distribution system. Simultaneous placement of both renewable DGs provides maximum benefits. The comparison between proposed and existing techniques have been presented which confirms that the suggested technique gives the superior result.
\end{abstract}

Keywords : Optimal placement and size of DGs, Adaptive particle swarm optimization (APSO), Renewable source DG, Biomass, PV-Solar.

\section{INTRODUCTION}

$\mathrm{N}$ owadays, researchers take interest in Distributed generation (DG) and how this concept of DG is implemented in distribution system. Distributed Generation is different from standard generation. In present days, it is difficult for utilities to meet load demand due to rapid growth of load demand and for this solution is DG. In the literature, various types of DG definitions are available based on their rating and based on their location. The possible size of DG is up to $50 \mathrm{MW}$ as suggested by electrical power research institute [1]. Renewable DGs such as Wind, Solar and Biomass etc. are purposely installed in distribution system for taking benefits such as voltage profile improvement, reduction in active power \& reactive power losses, enhancement in reliability and quality of power. DG should placed and sized optimally because if it will not placed or sized optimally, it will give worst result.

Different types of methodology are available in various literatures to discover optimal allocation and size of multiple DGs with various objective functions. Lee and Park [2] have developed analytical methodology to discover optimal DG size and placement using Kalman filter approach for optimal DG planning (size \& location). Based on multiobjective

Revised Manuscript Received on July 22, 2019.

Kumari Sandhya Rani, Electrical Engg.Dept., NIT, Durgapur, WB, India,

Surajit Sannigrahi, Electrical Engg. Dept., NIT, Durgapur, WB, India,

Parimal Acharjee, Electrical Engg. Dept, NIT, Durgapur, WB, India,

Aashish Kumar Bohre, Electrical Engg. Dept., NIT, Durgapur, WB, India, functions based approach to optimize multiple DGs is presented in [3-5]. Different methods to plant DG effectively in the distribution system including high penetration level are proposed in [6-9]. For obtaining optimal placement and sizing Keane and Mally [10] have proposed linear programming based method considering different constraints. Soumyabrata and Debapriya [11] have presented a method to choose optimal wind DG and PV solar DG size and optimal placement of capacitor. In this literature they have analyzed the impact of system load growth considered seasonal variation in load and power generated by renewable sources. Srinivasa Rao and D. Das [12] have proposed an approach to determine DG placement and size on the basis of sensitivity analysis using GA. This paper also considered average hourly variation of load. K.R Devabalaji and K. Ravi [13] have proposed bacterial foraging optimization technique to discover optimal size of multiple DGs and DSTATCOM.

Murthy and Kumar [14] have proposed Novel method for optimal DG planning. This paper also presents the comparison for optimal DG allocation methods on the basis of sensitivity approaches. Duong Quoc et al. [15] have reported distributed generation units (nondispatchable and dispatchable renewable DGs) placement to minimize losses of distribution system. Kayal P \& Chanda C.K. [16] have proposed a method to find allocation of wind DG and solar DG to enhancement voltage stability and minimization of power loss. In [17] A.M. El-Zonkoly planned multi-DG units (size \& location) based on multi-objective function approach including different-different load models in distribution network. In [18] Aashish et al. used soft computing technique in practical distributed system to obtain optimal DG place and size, also they have developed an effective methodology to improve technical and economical benefits. In [19] Sriparna et al. used Genetic Algorithm to determine DG and Battery storage system deployment for distribution network including different aspects.

Solar power generation is intermittent in nature and Biomass DG is dispatchable in nature. Presented work includes load variation and solar power generation to achieve optimal DG size and location for the 94-bus portuguese radial network. The simultaneous placement of both DGs gives the better result than individually placed DG including technical and economical analysis is presented in this paper. 


\section{Problem Formulation}

\section{A. Objective Function}

To decide optimal allocation and size of a DG, a combination of objective functions is formulated by including effect of both technical factors as well as economic factors by deciding suitable weights based on its priority and which is expressed as:

$$
\operatorname{Max} \mathrm{F}=\mathrm{W}_{1} * \mathrm{ITAPL}+\mathrm{W}_{2} * \mathrm{IVD}+\mathrm{W}_{3} * \mathrm{IEF}
$$

Where $\mathrm{W}_{1}, \mathrm{~W}_{2}$ and $\mathrm{W}_{3}$ are technical and economic indices weight factors of multiobjective function.

The maximization of objective function $(\operatorname{Max} F)$ is performed to decide the optimal place and size of different type of DGs including various operational constraints as given below.

DG capacity Constraints Voltage magnitude limit constraint

$$
\begin{aligned}
& 0 \leq P_{D G P V} \leq P_{L}^{\max } \\
& 0 \leq P_{D G B M} \leq P_{L}^{\max }
\end{aligned}
$$

$$
V_{\min } \leq V_{i} \leq V_{\max }
$$

\section{B. System Performance Indices}

\section{i) Index of total active power loss (ITAPL)}

The ITAPL equation is given by the ratio of net substation active power supplied without and with DG integration and active power injected on $\mathrm{k}^{\text {th }}$ bus by DG.

$$
I T A P L=\frac{\left(\mathrm{V}_{\mathrm{S}} \mathrm{I}_{\mathrm{S}}^{*}\right)^{\text {Base }}-\sum_{i=2}^{\mathrm{NB}} \mathrm{P}_{\mathrm{Li}}}{\left(\mathrm{V}_{\mathrm{S}} \mathrm{I}_{\mathrm{S}}^{*}\right)^{\mathrm{DG}}+\sum_{k=1}^{\mathrm{NDG}} \mathrm{P}_{\mathrm{DGi}}-\sum_{i=2}^{\mathrm{NB}} \mathrm{P}_{\mathrm{Li}}}
$$

Where, $\left(\mathrm{V}_{\mathrm{S}} \mathrm{I}_{\mathrm{S}}^{*}\right)^{\text {Base }}$ and $\left(\mathrm{V}_{\mathrm{S}_{\mathrm{S}}}\right)^{\mathrm{DG}}$ are the total substation active power supplied without DG and with DG integration respectively. $\mathrm{P}_{\mathrm{DGi}}$ is active power injected on $\mathrm{k}^{\text {th }}$ bus by DG. $\mathrm{P}_{\mathrm{Li}}$ is total load. NB is Total no. of buses. NDG is No. of DG optimally allocated within the distribution system.

\section{ii) The voltage deviation Index(IVD)}

IVD is defined by ratio of difference between base voltage magnitude and voltage magnitude with DG to base voltage. Mathematically, the IVD can be written as:

$$
I V D=\max _{i=2}^{N B}\left(\frac{V_{\text {base }}}{\left|V_{\text {base }}-V_{D G i}\right|}\right)
$$

Where $V_{D G i}$ and $V_{\text {base }}$ are the $\mathrm{i}^{\text {th }}$ node voltage magnitude with DG and base case, respectively.

\section{iii) Index of economic factor (IEF)}

The economic factor have important role while plan different type DG and capacity of DG, long term planning and utilities optimal operation as well as customer optimal operation.

When DGs are connected in distribution network, benefits are estimated based on effective cost saving of energy. Some factors for economy analysis are given as follows:

\section{- $\quad$ Effective cost saving of energy (CSE)}

Due to DG optimal size and location, the active power losses are reduced significantly. The cost effective saving of annual energy is planned for four different load levels. It can be mathematically formulated as:

$$
\mathrm{CSE}=K_{e} *\left\{\sum_{i=1}^{l l}\left(P_{s i}-P_{s i}^{D G}\right) * T\right\} * N_{y}
$$

Where $P_{s i}$ and $P_{s i}^{D G}$ are represents power injected without DG as well as with DG penetration for total T hours in a year. $N_{y}$ is number of years that is considered as 20 . The $K_{e}$ is assumed as $\$ 0.12 / \mathrm{KWh}$, which is a constant value used to select the various values cost values.

\section{- Total Installation cost(TIC)}

The installation costs (IC) is calculated to allocate two types of DGs as given below:

$$
\mathrm{IC}=\left(\mathrm{C}_{\mathrm{DGPV}} * \mathrm{P}_{\mathrm{DGPV}_{-} \mathrm{f}}+\mathrm{C}_{\mathrm{DGBM}_{1}} * \mathrm{P}_{\mathrm{DGBM}}\right)
$$

Equated yearly installation (EYI) for $N_{y}$ number of years at $\mathrm{r}$ rate as given in equation no. (6):

$$
\mathrm{EYI}=\mathrm{IC} * \frac{\left(r *(r+1)^{N y}\right)}{\left((r+1)^{N}-1\right)}
$$

Hence, Total installation cost for $N_{y}$ years is

$$
\mathrm{TIC}=\mathrm{EYI} * N_{y}
$$

In this work, $\mathrm{r}$ is rate of interest and considered as $10 \% . \mathrm{C}_{\mathrm{DGPV}}$ and $\mathrm{C}_{\mathrm{DGBM}}$ is installation cost of Solar DG and Biomass DG, respectively.

\section{- Operation and maintenance expenditure (OME)}

The annual maintenance and operation expenditure for two DGs installed in the distribution network is given by following equations:

$$
\mathrm{OME}=\left\{\sum_{i=1}^{l l}\left(\mathrm{MC}_{\mathrm{DGPV}} * \mathrm{P}_{\mathrm{DGPV}}+\mathrm{MC}_{\mathrm{DGBM}} \mathrm{P}_{\mathrm{DGBM}}\right) * \mathrm{~N}_{\mathrm{y}} * \mathrm{~T}\right\}
$$

Where, $\mathrm{MC}_{\mathrm{DGPV}}$ and $\mathrm{MC}_{\mathrm{DGBM}}$ are $\mathrm{PV}$ solar and biomass $\mathrm{DG}$ the operation and maintenance cost at $i^{\text {th }}$ load level respectively. And $P_{D G P V}$ and $P_{D G B M}$ are $\mathrm{PV}$ solar and biomass DG real power injection.

Therefore, the net benefit (S) caused by DG integration in distribution system is given as:

$$
\text { NET BENEFIT }(\mathrm{S})=(\mathrm{CSE}-(\mathrm{TIC}+\mathrm{OME}))
$$

Hence index of economic factor (IEF) is ratio of saving of annual cost-effective energy (CSE) to the sum of total installation cost (TIC) and operation and maintenance expenditure (OME) .The mathematically formulation for IEF is as follows:

$$
\mathrm{IEF}=\frac{\mathrm{CSE}}{(\mathrm{TIC}+\mathrm{OME})}
$$




\section{MOdELING OF HYBRId SySTEM}

\section{A. Variation of system load}

The distribution system daily load profile is considered for 24 hours in a day, which is assumed same value for all 365 days for a year. This one day load level is divided into four parts as given below

1. Duration from 12.00 AM to 6.00 AM

2. Duration from 6.00 AM to $12.00 \mathrm{PM}$

3. Duration from 12.00 PM to 6.00 PM

4. Duration from 6.00 PM to $12.00 \mathrm{AM}$

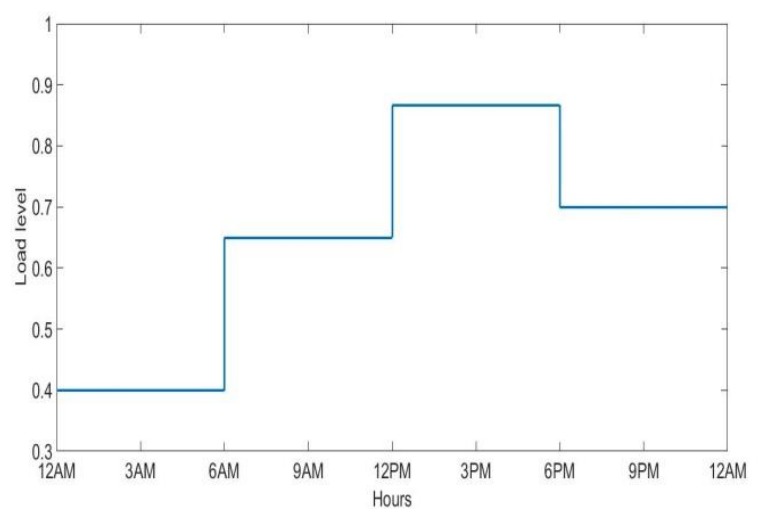

Fig. 1. The considered daily load profile for system

B. Variation of output power of Solar and Biomass DG In recent research work, the two solar and biomass based DGs are placed on the Portuguese RDS 94-bus test system which has unity power factor.

Power generation of Solar DG is intermittent in nature and generation of average power of solar-PV for solar plant is given below:

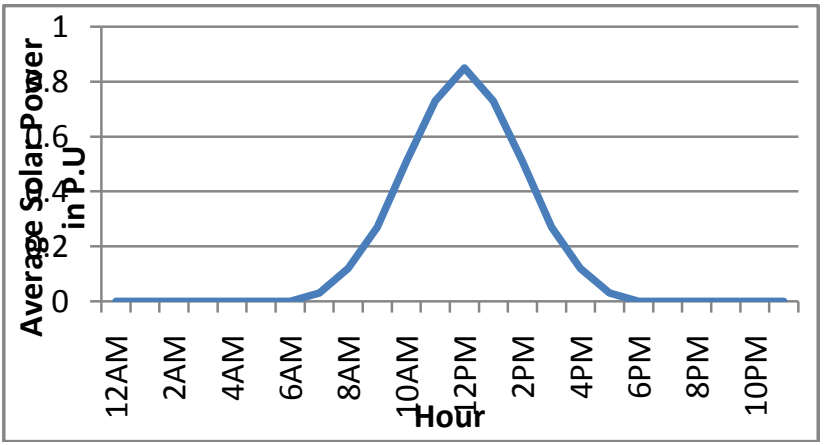

Fig. 2. Average solar power generation in a typical day

Fossil fuels are limited but biomass DG is dispatchable in nature and it is constant throughout the day. Average Biomass power generation is given below:

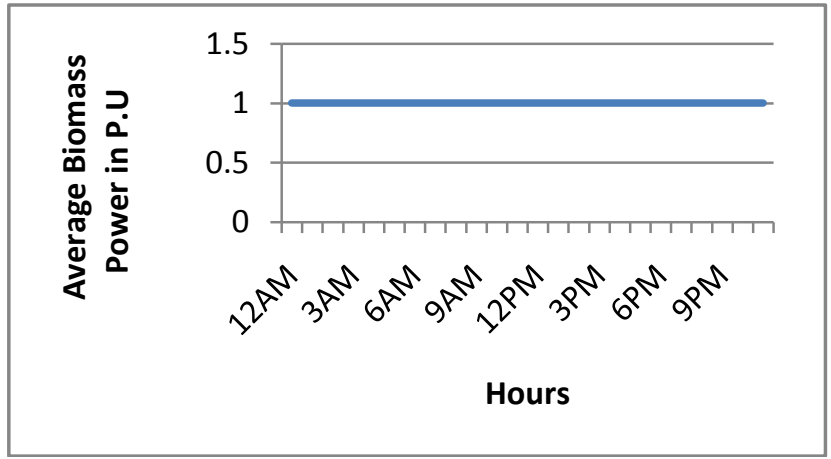

Fig. 3. Average Biomass power generation in a typical day C. Adaptive Particle Swarm Optimization
Kennedy and Eberhart in 1995 introduced an effective swarm based optimization technique on the basis of intelligence and movement of swarms. That optimization technique is named as particle swarm optimization technique. An accelerated version of PSO is called as APSO. It works on same concept of movement of swarm to locate the optimum value in PSO.

General Equations of APSO:

Update particle velocity:

$$
\mathrm{V}_{\mathrm{i}}^{\mathrm{t}+1}=\mathrm{V}_{\mathrm{i}}^{\mathrm{t}} * \mathrm{~W}_{\mathrm{t}}+\mathrm{C}_{1} * \mathrm{U}_{1}^{\mathrm{t}} *\left(\mathrm{pb}_{\mathrm{i}}^{\mathrm{t}}-\mathrm{P}_{\mathrm{i}}^{\mathrm{t}}\right)+\mathrm{C}_{2} * \mathrm{U}_{2}^{\mathrm{t}} *\left(\mathrm{gb}^{\mathrm{t}}-\mathrm{P}_{\mathrm{i}}^{\mathrm{t}}\right)
$$

Move particles to their new positions:

$$
\mathrm{P}_{\mathrm{i}}^{\mathrm{t}+1}=\mathrm{P}_{\mathrm{i}}^{\mathrm{t}}+\mathrm{V}_{\mathrm{i}}^{\mathrm{t}+1}
$$

Where

$$
\begin{aligned}
& \mathrm{P}_{\mathrm{i}}^{\mathrm{t}}=\text { Particle position } \\
& \mathrm{V}_{\mathrm{i}}^{\mathrm{t}}=\text { Particle velocity } \\
& \mathrm{pb}_{\mathrm{i}}^{\mathrm{t}}=\text { Pbest value } \\
& \mathrm{gb}^{\mathrm{t}}=\text { Gbest value } \\
& \mathrm{C}_{1}, \mathrm{C}_{2}=\text { Constriction factor }
\end{aligned}
$$

APSO updates acceleration in addition to position and velocity according to its variable weight function. Due to this APSO is faster than PSO .

Equation for weight function:

$$
\begin{aligned}
& \mathrm{W}_{\mathrm{t}}=\mathrm{W}_{\max }-\frac{\left(\mathrm{W}_{\max }-\mathrm{W}_{\min }\right) * \text { present_iteration }}{\text { maximum _iteration }} \\
& \text { Where, } \\
& \mathrm{W}_{\max }=0.9 ; \\
& \mathrm{W}_{\min }=0.4
\end{aligned}
$$

START

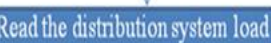

and line data and read Solar and Biomass data.
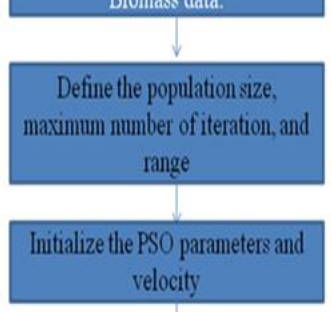

Set iteration $=1$

Randomly generate initial position and velocity of each particle an get pbest and gbest of population
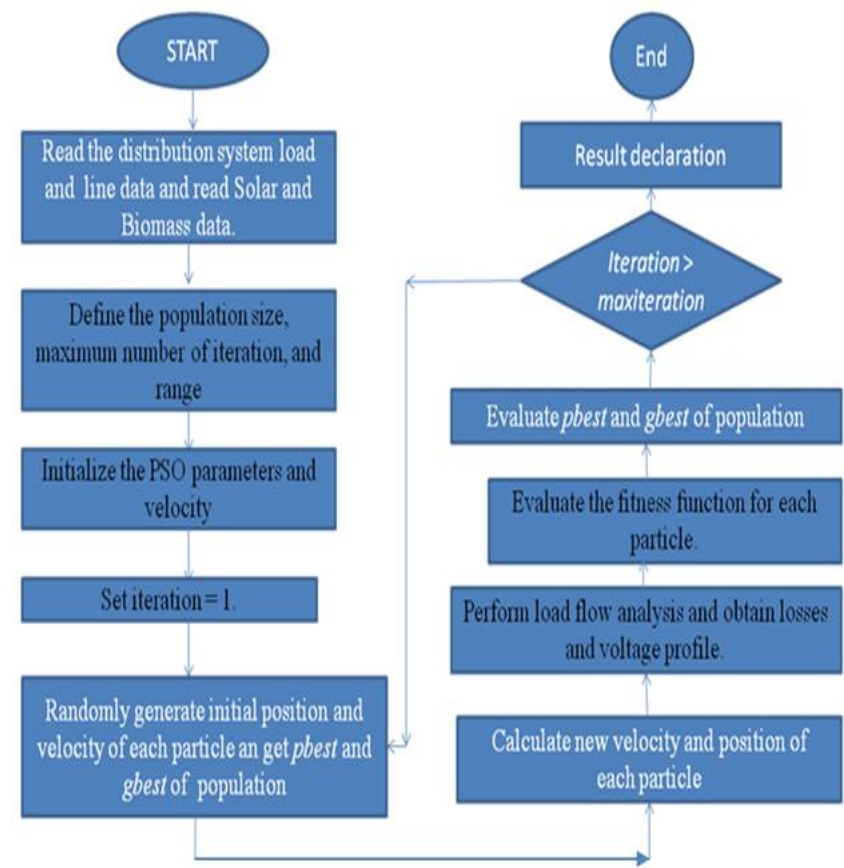

Fig. 4. Flow chart of Adaptive PSO Implementation

Published By: 


\section{Determining Optimal Size and Placement of Renewable DG Considering Variation of Load}

\section{RESULTS AND DiscuSSIONS}

The four different cases results to investigate size and allocation of renewable DGs like PV-solar and biomass DGs for time varying load as well as the time varying PV-solar curve are discussed in this section.

Case I: The Base case (i.e. Without DG)

Case II: Only solar DG

Case III: Only biomass DG

Case IV: Both solar and biomass DG

All parameters are specified in table 1. Determination of optimal place and size of renewable DGs i.e. solar and biomass DGs are conducted on 94-bus Portuguese RDS (Radial distribution system). The base voltage of proposed system is $15 \mathrm{kV}$ and net active \& reactive load is $(4.797+j 2.324)$ MVA. Above one day load schedule is divided into four parts as shown in fig.1. The obtained results for different cases at average load condition are given in table-2. The optimum size and place of both (Solar and Biomass) DG is demonstrated in table-2. The optimal place and size planning of both renewable DGs are obtained by performing the maximization of above objective function (i.e Max F) with APSO optimization with appropriate weighting factors. The presented results disclose that system indices ITAPL, IVD and IEF are showing better results for fourth case i.e. when both DGs are placed simultaneously in distribution network. Table 2 shows the optimum place and size of different DGs in different cases and also shows the value of ITAPL, IVD and IEF for three different cases. The table 2 confirms that ITAPL is obtaining highest value for simultaneous placement of both DG, Also the case II obtained lowest value. Table 3 illustrates the economics aspect i.e. installation cost, operation and maintenance cost, benefits and net benefits for different cases that is considered in proposed work. Here, the highest value is achieved for the net benefit while plan simultaneous placement of both DG case which is given in table 3 . The bus voltage graph of proposed distribution system is revealed in Fig. 5, 6, 7 and 8 for different levels of load. The significant improvement in system bus voltages is observed for all with DG cases than base case. And it is also best for simultaneous placement of both DGs in second and third load level. But in first and fourth load levels only placement of biomass DG gives the best result because at that time solar DG will not be operated. Fig. 9 demonstrates the graphical representation for active power losses of the test system at the four different load levels. As demonstrated in the figure, a significant reduction in total active power loss is noticed for all cases than base case. For first and second load levels it is best for simultaneous placement of both DGs whereas, for third and fourth load levels only placement of biomass DG gives the best result because at that time solar power is given zero.

Table-I: The DGs parameters for economic analysis and load growth

\begin{tabular}{|l|l|}
\hline Parameters & Value \\
\hline The solar DG installation cost & $\$ 3090 / \mathrm{kw}$ \\
\hline The biomass DG installation cost & $\$ 1390 / \mathrm{kw}$ \\
\hline The solar DG maintenance and operation cost & $\$ 0.01 / \mathrm{kw}$ \\
\hline The biomass DG maintenance and operation cost & $\$ 0.036 / \mathrm{kw}$ \\
\hline$K_{e}$ & $\$ 0.12 / \mathrm{kwh}$ \\
\hline$N_{y}$ & 20 years \\
\hline R & $10 \%$ \\
\hline
\end{tabular}

Table-II: The test system results for average load level

\begin{tabular}{|l|l|l|l|l|l|}
\hline Cases & $\begin{array}{l}\text { Optimal } \\
\text { Place }\end{array}$ & $\begin{array}{l}\text { Optimal } \\
\text { Size(KW) }\end{array}$ & ITAPL & IVD & IEF \\
\hline \multirow{2}{*}{$\begin{array}{l}\text { Case } \\
\text { II }\end{array}$} & 52 & 2096.2 & 1.855 & 1.7089 & 2.9133 \\
\cline { 2 - 4 } $\begin{array}{l}\text { Case } \\
\text { III }\end{array}$ & 21 & 1922.2 & & & \\
\hline \multirow{2}{*}{$\begin{array}{l}\text { Case } \\
\text { IV }\end{array}$} & 25 & 1617.2 & 2.798 & 4.2112 & 6.1324 \\
\cline { 2 - 3 } & 50 & 881.2 & & & \\
\cline { 2 - 3 } & 20 & 1196.3 & 4.553 & 4.5110 & 3.8923 \\
\cline { 2 - 3 } & 59 & 770.4 & & & \\
\hline
\end{tabular}

Table-III: Net economic benefit after the planning period

\begin{tabular}{|l|l|l|l|l|}
\hline Cases & $\begin{array}{l}\text { Installation } \\
\text { Cost }\end{array}$ & $\begin{array}{l}\text { Maintenance } \\
\text { Cost }\end{array}$ & Benefit & Net Benefit \\
\hline $\begin{array}{l}\text { Solar } \\
\text { DG }\end{array}$ & $\$ 29165000$ & $\$ 293300$ & $\$ 85822000$ & $\$ 56363000$ \\
\hline $\begin{array}{l}\text { Biomas } \\
\text { s DG }\end{array}$ & $\$ 10051000$ & $\$ 808870$ & $\$ 66594000$ & $\$ 55735000$ \\
\hline $\begin{array}{l}\text { Solar } \\
\text { DG } \\
\text { \&Biom } \\
\text { ass DG }\end{array}$ & $\$ 21127000$ & $\$ 634440$ & $\$ 84702000$ & $\$ 62941000$ \\
\hline
\end{tabular}

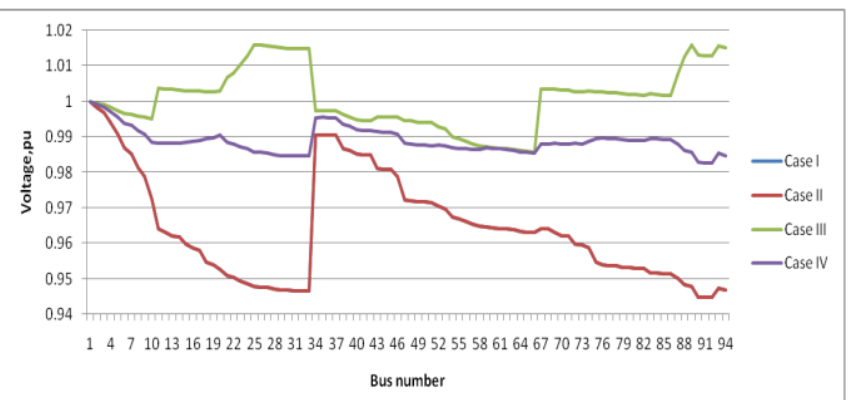

Fig. 5. The voltage profile for first load level (12AM to 6AM) of 94-bus (RDS) radial distribution system

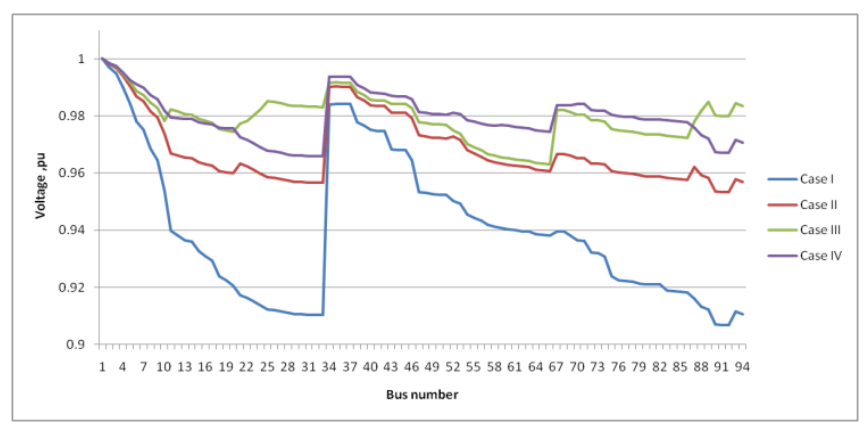

Fig. 6. The voltage profile for second load level (6AM to 12PM) of 94-bus RDS.

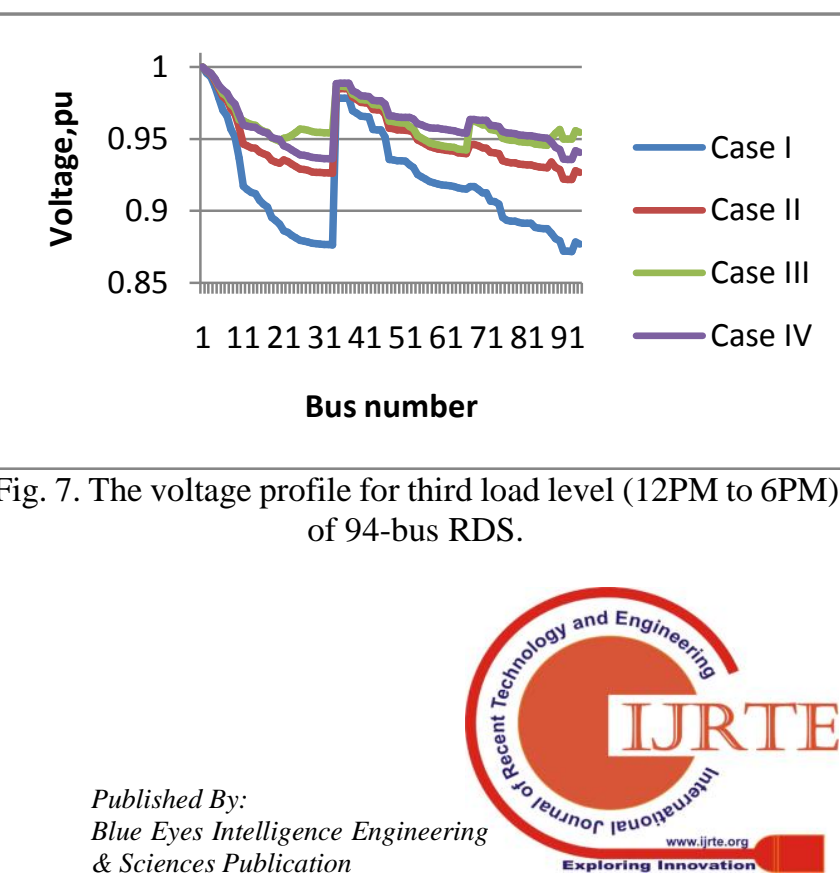




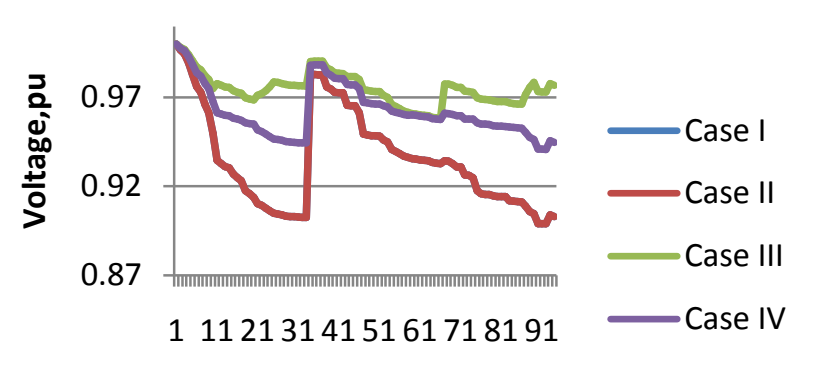

Bus number

Fig. 8. The voltage profile for fourth load level (6PM to 12AM) of 94-bus test system.

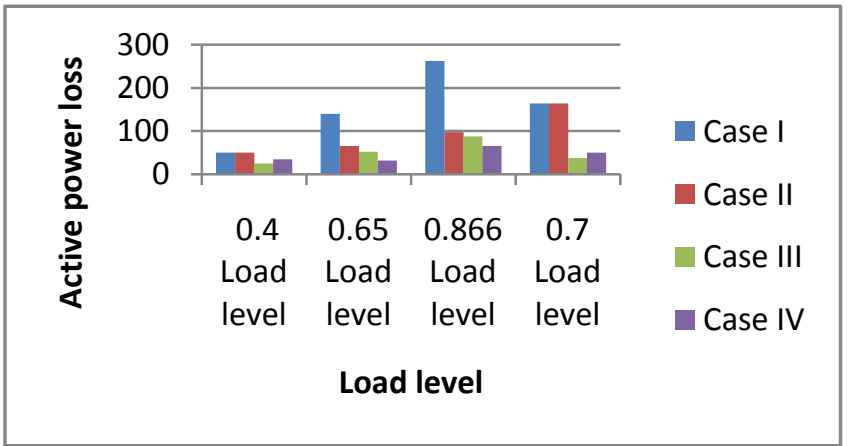

Fig. 9. The Active power loss considering different load levels.

\section{Conclusion}

The APSO has been proposed to investigate the DGs optimal place and size in distribution network. Two different DG type namely solar-PV and biomass DG have been considered. To allocate those DGs, a time varying load including with time varying solar power generation curve has been proposed. Here our aim by planning DGs within the distribution system is to enhance voltage profile and decrease active power loss for whole system. To scrutinise DG optimal place and size, the load has been subdivided into four levels. Depending upon the various conditions, four cases have been presented. The results of all four cases have been compared and observed that the combination of solar as well as biomass DG i.e. case IV offers best results in term of index of total active power loss, voltage index and economic factor for second(6AM to 12PM) and third(12PM to 6PM) load level . In first (12AM to 6AM) and fourth (6PM to 12AM) load levels solar DG power output has been considered as zero as shown in figure 2 . Hence, for first (12AM to 6AM) and fourth (6PM to $12 \mathrm{AM}$ ) load levels case III provides the best result on the basis of system index as voltage index, active power loss, and economic factor.

\section{REFERENCES}

1. Ackermann T, Andersson G, Söder L. :Distributed generation: a definition1. Electric power systems research. 2001 Apr 20; 57(3):195-204

2. Lee, Soo-Hyoung, and Jung-Wook Park.: Selection of optimal location and size of multiple distributed generations by using Kalman filter algorithm. IEEE Transactions on Power Systems24.3 (2009): 1393-1400.

3. Nayanatara, C., J. Baskaran, and D. P. Kothari.: Hybrid optimization implemented for distributed generation parameters in a power system network. International Journal of Electrical Power \& Energy Systems 78 (2016): 690-699.

4. Jamil, Majid, and Ahmed Sharique Anees.: Optimal sizing and location of SPV (solar photovoltaic) based MLDG (multiple location distributed

generator) in distribution system for loss reduction, voltage profile improvement with economical benefits. Energy 103 (2016): 231-239.

5. Abu-Mouti, Fahad S., and M. E. El-Hawary.: Optimal distributed generation allocation and sizing in distribution systems via artificial bee colony algorithm. IEEE transactions on power delivery 26.4 (2011): 2090-2101.

6. Amutha, W. Margaret, and V. Rajini.: Cost benefit and technical analysis of rural electrification alternatives in southern India using HOMER. Renewable and Sustainable Energy Reviews 62 (2016) 236-246.

7. Blaabjerg, Frede, and Dan M. Ionel.: Renewable energy devices and systems-state-of-the-art technology, research and development, challenges and future trends. Electric Power Components and Systems 43.12 (2015): 1319-1328.

8. Colmenar-Santos, Antonio, et al.: Distributed generation: A review of factors that can contribute most to achieve a scenario of DG units embedded in the new distribution networks. Renewable and Sustainable Energy Reviews 59 (2016): 1130-1148.

9. Jordehi, Ahmad Rezaee. : Allocation of distributed generation units in electric power systems: A review. Renewable and Sustainable Energy Reviews 56 (2016): 893-905.

10. Keane, Andrew, and Mark O'Malley.: Optimal allocation of embedded generation on distribution networks. IEEE Transactions on Power Systems 20.3 (2005): 1640-1646.

11. Barik, Soumyabrata, and Debapriya Das.: Determining the Sizes of Renewable DGs Considering Seasonal Variation of Generation and Load and Their Impact onSystem Load Growth. IET Renewable Power Generation (2017).

12. Gampa, Srinivasa Rao, and D. Das.: Optimum placement and sizing of DGs considering average hourly variations of load. International Journal of Electrical Power \& Energy Systems 66 (2015): 25-40.

13. Devabalaji, K. R., and K. Ravi.: Optimal size and siting of multiple DG and DSTATCOM in radial distribution system using bacterial foraging optimization algorithm. Ain Shams Engineering Journal 7.3 (2016): 959-971.

14. Murthy, V. V. S. N., and Ashwani Kumar.: Comparison of optimal DG allocation methods in radial distribution systems based on sensitivity approaches. International Journal of Electrical Power \& Energy Systems 53 (2013): 450-467.

15. Hung, Duong Quoc, N. Mithulananthan, and Kwang Y. Lee.: Optimal placement of dispatchable and nondispatchable renewable DG units in distribution networks for minimizing energy loss. International Journal of Electrical Power \& Energy Systems 55 (2014): 179-186.

16. Kayal, Partha, and C. K. Chanda.: Placement of wind and solar based DGs in distribution system for power loss minimization and voltage stability improvement. International Journal of Electrical Power \& Energy Systems 53 (2013): 795-809.

17. El-Zonkoly, A. M.: Optimal placement of multi-distributed generation units including different load models using particle swarm optimization. Swarm and Evolutionary Computation1.1 (2011): 50-59.

18. Bohre, Aashish Kumar, Ganga Agnihotri, and Manisha Dubey.: Optimal sizing and sitting of DG with load models using soft computing techniques in practical distribution system. IET Generation, Transmission \& Distribution 10.11 (2016): 2606-2621.

19. Ghatak, Sriparna Roy, Surajit Sannigrahi, and Parimal Acharjee. Optimal deployment of renewable DG and battery storage system in distribution system considering techno-economic, environment and reliability aspects. 2018 International Conference on Power, Instrumentation, Control and Computing (PICC). IEEE, 2018.

\section{AUTHORS PROFILE}

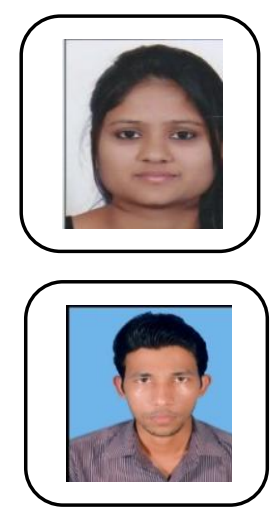

Kumari Sandhya Rani received M.Tech degree in Electrical Engg from NIT Durgapur, WB, in 2019. She has done B.Tech from College of Technology and Engineering Udaipur, in 2016. Her research interests include Power system and its application such as in Distribution System Analysis, Demand Side Management and Optimization Technique.

Surajit Sannigrahi received the B.Tech. degree (2012) from Meghnad Saha Inst. of Tech., Kolkata and M.Tech. degree (2016) from NIT Durgapur, Durgapur, India, in 2016. Currently he is Ph.D. scholar in Electrical Engg. Department, NIT Durgapur, WB 


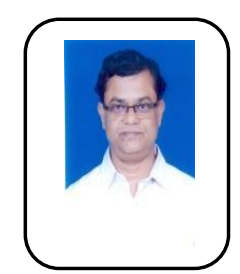

Dr. Parimal Acharjee passed B.E.E. from Jalpaiguri Govt. Engg. College, North Bengal University and completed M.E.E. and $\mathrm{Ph}$. D. from Jadavpur University, Kolkata, India. He has three years Industrial Experience and 18 years teaching experience. He continued his teaching profession in MCKVIE, Howrah, BPPIMT, Kolkata, NIT Silchar, India. He is presently working in Electrical Engineering Department, NIT Durgapur, India as a Professor. His current research interest is the application of soft-computing techniques in various advanced power system problems, Distribution Generation, FACTS Devices, and Smart Grid.

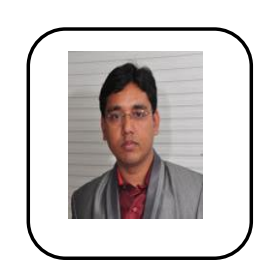

Dr. Aashish Kumar Bohre has received his B.E degree (2009) in Electrical and Electronics engineering from UIT-RGPV Bhopal, M.P., India; M.Tech. degree (2011) in Power System and Ph.D. degree (2016) in Electrical Engineering from Maulana Azad National Institute of Technology (MANIT), Bhopal. At the moment he is Assistant Professor in Electrical Engineering Department at National Institute of

Technology (NIT), Durgapur, WB, India. He is the author of several articles published in reputed journals and conferences. His research interest includes distribution system operation and planning, distributed generation, power system optimization, smart grid, renewable energy, power system stability, transient analysis, and soft computing techniques etc. 